\title{
Aleitamento materno: a visão das puérperas
}

\section{Breastfeeding: the sight of puerperas}

\section{Abuelo Materno: una vision de las puérperas}

\author{
Cristina Alencar Barreto', Leila Rangel da Silva", Marialda Moreira Christoffel"
}

\footnotetext{
'Enfermeira. Aluna do Programa de Pós-Graduação em Enfermagem - Mestrado da Universidade Federal do Estado do Rio de Janeiro (PPGEnf/UNIRIO). E-mail: cris barreto2005@yahoo.com.br.

" Docente do Departamento de Enfermagem Materno-Infantil da Escola de Enfermagem Alfredo Pinto da Universidade Federal do Estado do Rio de Janeiro (EEAP/UNIRIO). Orientadora do Estudo. E-mail: rangel.leila@gmail.com.

II' Docente do Departamento Materno-Infantil da Escola de Enfermagem Anna Nery da Universidade Federal do Rio de Janeiro. E-mail: marialdanit@gmail.com.
}

\section{RESUMO}

O aleitamento materno é de suma importância para o binômio mãe-filho, tanto do ponto de vista físico, como psicológico. A maioria das mulheres experenciam o aleitamento materno e necessita do apoio dos profissionais de saúde. Esta pesquisa teve como objetivo conhecer a visão das puérperas em relação ao cuidado prestado pelos profissionais de saúde quanto à prática da amamentação. Trata-se de um estudo descritivo exploratório, realizado com 50 puérperas em uma maternidade no município do Rio de Janeiro, no período de Agosto a Dezembro de 2006. Das entrevistadas, 68\% têm idade entre 20 e 29 anos, 40\% têm baixa escolaridade, 64\% são multíparas. Em relação a gestação atual 72\% referiram parto normal, $94 \%$ das mulheres realizaram o prénatal, destes $30 \%$ foi acompanhado pela enfermeira. O estudo evidenciou que 58\% não foram orientadas quanto à prática da amamentação, 38\% referiram falta de orientação prestada por algum profissional e $42 \%$ sentiram dificuldade para amamentar. A prática do aleitamento materno deve ser uma das principais ações de profissionais de saúde desde o pré-natal até o puerpério sensibilizando para o manejo e apoio à mulher, recémnascido e família nos diferentes cenários.

Descritores: Aleitamento materno; Enfermagem; Saúde da mulher; Cuidado do lactente; Período pós-parto.

\section{ABSTRACT}

Breastfeeding is extremely important to the mother/baby, such as the physical and psychological points of view. Most women experience breastfeeding and need the support of health professionals. This research aimed to meet the vision of the women in relation to the care provided by health care professionals about the practice of breastfeeding. It is a descriptive exploratory study, conducted with 50 women in a maternity in the of Rio de municipal district of Rio de Janeiro. From the respondents, $68 \%$ are aged between 20 and 29 years old, $40 \%$ have low education, and $64 \%$ are multiparous. Regarding to pregnancy current $72 \%$ said normal delivery, $94 \%$ of the women performed the pre-natal, and the $30 \%$ were accompanied by the nurses. The study showed that $58 \%$ were not targeted on the practice of breastfeeding, 38\% said lack of guidance provided by a professional and $42 \%$ had trouble breastfeeding. The practice of breastfeeding to be one of the main actions of health professionals from pre-natal to the puerperium awareness of the management and support to women, newborns and family in different scenarios.

Descriptors: Breast feeding; Nursing; Women's health; I nfant care; Postpartum period.

\section{RESUMEN}

La lactancia materna es muy importante para la madre hijo, en tanto físicos como psicológicos. La mayoría de las mujeres en periodo de lactancia y necesita el apoyo de los profesionales de la salud. Este estudio tiene el objetivo de satisfacer la visión de la mujer en relación con la atención prestada por los profesionales de la salud acerca de la práctica de la lactancia materna. Se trata de un estudio exploratorio descriptivo, realizado con 50 mujeres en una maternidad en el municipio de Río de Janeiro. De los encuestados, 68\% tienen edades comprendidas entre los 20 y 29 años, el 40\% tiene un nivel bajo de educación, el 64\% son multíparas. En relación con el embarazo actual $72 \%$ dice normal, el $94 \%$ de las mujeres realizaron el pre-natal, el $30 \%$ fue acompañado por la enfermera. El estudio mostró que el $58 \%$ no fueron dirigidos en la práctica de la lactancia materna, el 38\% dice falta de orientación proporcionada por un profesional y el $42 \%$ tenía problemas de lactancia. La práctica de la lactancia materna como una de las principales acciones de los profesionales de la salud prenatal a la puerperio conocimiento de la gestión y apoyo a las mujeres, los recién nacidos y de la familia en distintas situaciones.

Descriptores: Lactancia materna; Enfermería; lactancia; La salud de la mujer; Cuidado do lactente; Periodo posparto. 


\section{NTRODUÇÃO}

No contexto do alojamento conjunto as puérperas recebem informações e orientações sobre a amamentação pelos profissionais de saúde. Muitas vezes, esse processo é uma prática impregnada por valores, costumes e culturas tanto dos familiares, tais como: leite fraco e insuficiente, uso de água e chá; por outro lado os profissionais de saúde que prescrevem o leite artificial ou referem ser o leite materno o melhor alimento e que "ela tem de amamentar", sem levar em consideração sua experiência ou vivência.

De acordo com a Portaria MS/GM no 1016, de 26 de agosto de 1993, alojamento conjunto “É um sistema hospitalar em que o recém-nascido sadio, logo após o nascimento, permanece ao lado da mãe, 24 horas por dia, num mesmo ambiente até a alta hospitalar"(1). Essa Portaria traz orientações quanto às vantagens do aleitamento materno: estimular e motivar o aleitamento materno, de acordo com as necessidades da criança, tornando a amamentação mais fisiológica e natural; a amamentação precoce provoca a contração do útero e de seus vasos, atuando como profilaxia das hemorragias pós-parto; favorecer a precocidade, intensidade, assiduidade do aleitamento materno, e sua manutenção por tempo mais prolongado; fortalecer os laços afetivos entre mãe e filho, através do relacionamento precoce; permitir a observação constante do recém-nascido pela mãe, o que a faz conhecer melhor seu filho e, possibilitar a comunicação imediata de qualquer anormalidade; oferecer condições à enfermagem de promover o treinamento materno, através de demonstrações práticas dos cuidados indispensáveis ao recém-nascido e a puérpera ${ }^{(1)}$.

Enquanto enfermeiras atuando no alojamento conjunto e ao conversar com essas mulheres, durante o cuidado prestado à mulher e ao recémnascido no alojamento conjunto, percebemos alterações físicas e emocionais que estão ocorrendo, além do transtorno vivenciado pela família, consequências psicológicas, sociais e financeiras que implicam em mudanças muitas vezes radicais. $\mathrm{Na}$ maioria das vezes, as mulheres não estão preparadas para enfrentar essas pressões da sociedade.

O puerpério é o período do ciclo gravídicopuerperal em que as modificações locais e sistêmicas, provocadas pela gravidez e parto, no organismo da mulher, retornam à situação do estado prégravídico $^{(2)}$. Nesta ocasião, a mulher tem necessidades de atenção física e psíquica. Nos momentos iniciais após o parto, a relação mãe-filho não estará ainda bem elaborada, portanto não se devem concentrar todas as atenções apenas na criança, pelo risco de que isso seja interpretado como desprezo às suas ansiedades ou queixas.

Assim, depreendemos que os profissionais de saúde envolvidos na assistência às puérperas devem estar atentos às necessidades apresentadas, reforçando a importância da amamentação (que certamente foi apresentada as gestantes no prénatal), ouvindo-as, oferecendo apoio e orientações pertinentes a estes e outros assuntos. Estes devem ajudá-las também a encontrar as respostas para suas dúvidas, respeitando este período de constantes alterações e de grande sensibilidade, considerando sempre o conhecimento prévio apresentado, sua cultura e valores.

Durante as atividades práticas na maternidade nos setores de sala de parto e alojamento conjunto tivemos a oportunidade de observar que muitas puérperas não eram orientadas pelos profissionais de saúde para amamentar seus recém-nascidos o mais precoce possível, para que isso acontecesse ainda na sala de parto. Evidências científicas ${ }^{(1,3)}$ comprovam que quanto mais cedo o recém-nascido for colocado ao seio, maior é a chance de se estabelecer o vínculo mãe-filho e menor é a possibilidade do desmame precoce.

As vantagens que a comunidade científica tem descoberto sobre a amamentação, e que têm sido divulgadas na sociedade, parecem não serem suficientes ou capazes de reverter à progressiva tendência ao desmame precoce, talvez pelo fato que a mulher durante a sua internação recebe orientações sobre amamentação, mas após a alta hospitalar, no domicílio ela necessite de um maior apoio dos profissionais de saúde, família e comunidade.

Apesar de muitas maternidades desejarem o título Hospital Amigo da Criança, muitas mulheres saem dessas instituições sem receber apoio e a orientação necessária para começar uma nova fase em sua vida e exercer a função de mulher-mãe com segurança, amamentando plenamente seu filho.

Certamente, o apoio e a orientação para a amamentação devem ser iniciados desde o período do pré-natal ao puerpério, porém por vezes constatamos que isto nem sempre é respeitado. Algumas mulheres ainda recebem, por ocasião de alta da maternidade, prescrição se necessário de leite artificial para complementar o leite materno. Esta realidade é facilmente identificada quando a consulta de puericultura é realizada e os lactentes apresentam decréscimo na curva do peso, além de diarréia ou constipação intestinal ocasionada muitas das vezes pelos leites artificiais, seu preparo e acondicionamento $^{(4)}$.

Com relação à realização das consultas de pósnatal, pelas puérperas, podemos listar os problemas precoces mais comuns que, de alguma forma, estão relacionados ao desmame precoce e alimentação mista: trata-se das pequenas fissuras mamilares e/ou ingurgitamento mamário por falha na pega; elas geram uma enorme ansiedade e precipitação na hora em que as mães decidem se vão permanecer ou não 
com o aleitamento materno exclusivo.

\section{RESGATANDO O PASSADO PARA REFLETIR SOBRE O FUTURO E A QUESTÃO DO ALEITAMENTO MATERNO}

O Ministério da Saúde vem desenvolvendo múltiplas ações para promover, proteger e apoiar o aleitamento materno nas últimas décadas tais como: Iniciativa Hospital Amigo da Criança (IHAC), Norma Brasileira de Comercialização de Alimentos para Lactentes e Crianças de Primeira Infância, Bicos, Chupetas e Mamadeiras (NBCAL), Bancos de Leite Humano, Método Canguru de Atenção Humanizada ao Recém-Nascido de Baixo Peso, e nos últimos anos a implantação da Iniciativa Unidade Básica Amiga da Amamentação (IUBAAM) ${ }^{(1)}$

Apesar de várias campanhas de incentivo e promoção do aleitamento materno, quer nas semanas mundiais de amamentação, quer na televisão e até por meio de cartilhas auto-explicativas e cartazes distribuídos nas Unidades Básicas de Saúde, as cifras em relação ao desmame precoce ainda não são as melhores. Se todos os brasileiros nascidos em 1995 tivessem sido amamentados até seis meses teriam sido poupados 423.8 milhões de litros de leite e 296.6 milhões de reais ${ }^{(2)}$.

Segundo o Manual de Capacitação de Equipes de Unidades Básicas de Saúde na Iniciativa Unidade Básica Amiga da Amamentação (IUBAAM), o desmame precoce surge na década de 70, ao longo do século $X X$, com a crescente urbanização, inserção da mulher no mercado de trabalho, industrialização e "marketing" dos leites modificados para lactentes. A prática do aleitamento materno, assim, decaiu no Brasil $^{(1)}$.

Para reverter o processo acelerado de desmame precoce no país, foi criado, em 1981, pelo Instituto Nacional de Alimentação e Nutrição (INAN), autarquia do Ministério da Saúde, em conjunto com o UNICEF e de parceria com o Ministério da Saúde e Previdência Social, o Programa Nacional de Incentivo ao Aleitamento Materno (PNIAM). O objetivo foi promover, proteger e apoiar a prática do aleitamento materno exclusivo até os seis meses, complementando-a com outros alimentos até os dois anos de idade ou mais ${ }^{(5-6)}$.

Em maio de 2001, a 54 Assembléia Mundial de Saúde aprovou, por unanimidade, a proposta brasileira de recomendar o aleitamento materno exclusivo por seis meses e sua complementação com outros alimentos até os dois anos de vida ou mais. Essa, então, passou a ser a recomendação da Organização Mundial de Saúde (OMS) e do Fundo das Nações Unidas para a Infância (UNICEF), sendo necessário um esforço coletivo da sociedade e do governo para implementá-la ${ }^{(5-6)}$.

O aleitamento materno exclusivo deve ser mantido até os seis meses de idade, quando outros alimentos líquidos e sólidos devem ser introduzidos na alimentação do lactente em paralelo com a manutenção da amamentação até o segundo ano de vida $^{(4)}$

No entanto, o desmame precoce e a amamentação artificial tem se tornado hábitos comuns, levando as taxas muitas vezes elevadas de mortalidade de crianças no primeiro ano de vida. As causas do desmame precoce são, em sua maioria, ligadas às mudanças dos valores sociais e culturais. Além da alta taxa de urbanização, aparecem também como causas a multiplicidade de mitos referentes ao leite materno, como "leite ralo e não nutritivo", e o desrespeito às leis trabalhistas. É lamentável ainda a pouca credibilidade e divergências de opinião entre os profissionais de saúde que assistem a mulher no ciclo gravídico-puerperal.

Neste sentido, 0 ato de amamentar reúne inúmeros fatores entrelaçados no âmbito social, econômico e cultural e que precisam ser discutidos em conjunto com as nutrizes e os profissionais de saúde, comprometidos com a saúde brasileira. Apesar da amamentação ser tema amplamente pesquisado na área da saúde da mulher e da criança, ainda são encontrados muitos aspectos a serem discutidos.

Não só para repensar a prática assistencial, mas unir também o saber-pensar ao saber-fazer. Só assim, os esforços beneficiarão a realidade dos profissionais de saúde, das puérperas e seus filhos, de seus companheiros e familiares e da sociedade. "O profissional que demonstrar segurança e confiança no primeiro encontro e afirmar na sua orientação que toda mulher é capaz de produzir o alimento para seu filho, certamente transmitirá segurança a nutriz, ao bebê e, consequentemente, ao companheiro e a seus familiares"(3).

Queremos ainda que este processo, ainda em construção, produza profissionais mais comprometidos, conscientes e revitalizados no campo da prática e da investigação científica. Assim como puérperas mais orientadas e capazes de adquirir conhecimento e segurança, prosseguindo neste caminho de novas descobertas. Pois "não [...] [há] resultados definitivos, ou seja, verdades acabadas"(7).

Desta forma, o objetivo do estudo foi conhecer a visão de puérperas em relação ao cuidado prestado pelos profissionais de saúde quanto à prática da amamentação.

\section{MÉTODOS}

Estudo descritivo, o qual tem como propósito observar, descrever e explorar aspectos de uma situação, sem a intenção de explicar ou compreender as causas subjacentes às variáveis em estudo ${ }^{(7)}$. O estudo foi realizado no alojamento conjunto de um hospital maternidade, referência para gestação de alto risco, que tem o Título Iniciativa Hospital Amigo 
da Criança em 2002, localizado no município do Rio de Janeiro.

A população do estudo foi constituída de 50 puérperas internadas no sistema de alojamento conjunto (no período que compreende o puerpério imediato - do 1 으 ao $10^{\circ}$ dia) e em processo de amamentação de seus filhos, no período de Janeiro a Fevereiro de 2006. Foram incluídas no estudo todas as puérperas que se dispuseram a participar da pesquisa e que assinaram o Termo de Consentimento Livre e Esclarecido, como forma de atender aos aspectos éticos e legais regidos pela Resolução de 196/96, foi elaborado um documento que foi encaminhado e aprovado pela Comissão de Ética em Pesquisa do Hospital Universitário Gaffree e Guinle, memorando CEP/nำ111/06.

A coleta de dados foi realizada com um questionário contendo questões fechadas referentes aos dados sócio-econômicos, obstétricos e o manejo do aleitamento materno e questões abertas que permitiram conhecer a visão destas mulheres enquanto internadas no alojamento conjunto e em relação à assistência prestada quanto à prática da amamentação. Além de “obter informações, o instrumento de coleta constitui condição social de interação humana, sem a qual não haverá ambiente favorável para produzir informações fidedignas"(7).

As entrevistas foram gravadas em fitas $\mathrm{K}-7$ e transcritas, facilitando, desta forma, o processo de análise. Esta técnica de coleta de dados permitiu não só que os sujeitos do estudo expressassem seus sentimentos. Os depoimentos das mulheres foram codificados em letras e números arábicos, de acordo com o dia da entrevista $(A 1, A 2, \ldots)$. Os dados analisados buscaram trazer o perfil das puérperas e a visão das mesmas em relação às práticas de amamentação.

\section{RESULTADOS E DISCUSSÃO}

Quanto ao perfil das puérperas entrevistadas, a maioria 68\% (34) é de jovens entre 20 e 29 anos; das 50 puérperas entrevistadas, 94\% (47) moram nas zonas norte e oeste do município; $40 \%$ (20) têm baixa escolaridade; a maioria 60\% (30) apresenta renda familiar de até dois salários mínimos, 58\% (29) não trabalham e 40\% (20) vivem em situação de união consensual com seus parceiros.

Em relação aos dados obstétricos, 64\% (32) tiveram mais de um filho; mais da metade $54 \%$ (27) realizaram aborto, sendo que $40 \%$ (20) passaram pela experiência de abortos espontâneos; 94\% (47) das mulheres fizeram o pré-natal, das quais $56 \%$ (28) no Posto de Saúde, 10\% (05) na Maternidade Carmela Dutra e 30\% (15) delas, fizeram o pré-natal com enfermeira. Quanto ao tipo de assistência ao parto e nascimento, $72 \%$ (36) referiram parto normal e $26 \%$ (13) cesáreas; $32 \%$ (16) tiveram intercorrências na gestação, das quais $12 \%$ (06) apresentaram hipertensão arterial sistêmica (HAS); durante o puerpério, $10 \%$ (05) tiveram intercorrências como HAS, ingurgitamento mamário e fissura mamilar.

Ao serem questionadas se receberam orientação durante a gravidez quanto à prática da amamentação, 42\% (21) responderam que sim, das quais $10 \%$ (05) foram alertadas sobre a importância da amamentação para o bebê, a necessidade de passar o próprio leite nos mamilos, a massagem nas mamas e a conveniência de amamentar até o sexto mês exclusivamente, sob livre demanda e pega correta; $58 \%$ (29) não foram orientadas e apenas $38 \%$ (19) sentiram falta de orientação prestada por algum profissional. Somente $24 \%$ (12) foram orientadas a colocar o bebê para mamar na sala de parto, conforme preconiza o Ministério da Saúde ${ }^{(4)}$, e expressaram sentimentos positivos tais como realização, alegria, felicidade, satisfação, emoção e alívio e os negativos de tremor, tontura, desconforto, dor e mal estar. Das 50 puérperas, 74\% (37) tiveram contato pele a pele ainda na sala de parto, $42 \%$ (21) sentiram dificuldade para amamentar no alojamento conjunto e descreveram, como problemas, as dificuldades na pega, dor nos mamilos/fissura, posicionamento incorreto do bebê ao seio, falta de preparo do mamilo, falta de leite, leite ralo, insegurança para amamentar e ingurgitamento mamário.

Durante o período de internação, 58\% (29) receberam orientações quanto aos cuidados com as mamas e $42 \%$ (21) não receberam qualquer assistência em relação à amamentação. Apenas $20 \%$ (10) referiram dúvidas sobre amamentação (cuidados com a mama ingurgitada, se as mamas vão encher de leite, se o bebê suga o suficiente para ficar alimentado e até que idade o bebê deve ser amamentado).

Podemos observar que em relação a baixa escolaridade e o poder aquisitivo, estas variáveis permitem descrever um perfil que pode interferir negativamente no processo de manutenção do aleitamento materno. Estudos feitos nas décadas de 70 e 80 apontaram o aumento da prática da amamentação no país e verificaram que essa tendência ocorreu entre mulheres de maior poder aquisitivo e de maior escolaridade ${ }^{(8)}$. Esses dados estão de acordo com os últimos dados coletados no Brasil, onde ocorre uma maior valorização dos benefícios do aleitamento materno nas classes mais favorecidas $^{(9)}$

Quanto à faixa etária foi constatado que quanto mais jovem a puérpera, mais imatura fisiológica e emocionalmente ela é. Isso pode indicar uma tendência ao desmame precoce ${ }^{(9-10)}$. Os dados do presente estudo apontam para esta tendência já que a maior porcentagem está entre as mulheres de 20 a 29 anos. Este fato, no entanto, não pode ser 
analisado isoladamente, pois existem os chamados fatores culturais, que influenciam na decisão de iniciar e permanecer amamentando.

Muito embora 94\% (47) das pesquisadas tivessem realizado o pré-natal, verificamos que $58 \%$ delas (29) não receberam orientação quanto à prática da amamentação durante a gravidez. A maioria destas últimas sentiu falta da orientação do profissional de saúde. Essa desinformação se refletiu no alojamento conjunto, onde $42 \% \quad$ (21) manifestaram dúvidas e dificuldades. Durante o prénatal, a gestante recebe orientações relativas a vários temas, entre eles a amamentação. Após o parto, em sistema de alojamento conjunto, é fundamental o incentivo, o apoio e a assistência quanto ao manejo da amamentação, de maneira que mãe e filho possam se adaptar a essa nova realidade cheia de desafios e descobertas ${ }^{(2,10)}$.

Ao identificar o local de realização do pré-natal, constatamos que somente $10 \%$ (05) das gestantes o realizaram na própria instituição em que a pesquisa foi realizada. Isto demonstra que mesmo que $56 \%$ (28) tenham comparecido à consulta no posto de saúde, essa assistência profissional pode estar falhando. Existem muitas razões que podem justificar a falta de orientação profissional às gestantes nas consultas de pré-natal, naquilo que diz respeito à prática da amamentação. Eles vão desde problemas administrativos da instituição, descompromisso e indisponibilidade até a falta de informação dos profissionais, excesso de gestantes agendadas em relação a um número insuficiente de profissionais e predomínio de um modelo biomédico que se evidencia nas consultas de pré-natal ${ }^{(11)}$.

Estudos apontam o pré-natal como o momento mais adequado, para que esta mulher seja assistida e apoiada em relação à amamentação, pois é ao iniciar sua experiência que ela toma as decisões a respeito de iniciar e permanecer amamentando. As outras ocasiões propícias são o parto e o puerpério imediato $^{(1-2)}$. A informação é fundamental para aumentar a autoconfiança da gestante e da puérpera, de maneira que elas possam superar as adversidades. Quando a informação adequada não é prestada às mulheres, profissionais de saúde e sociedade, o maior prejuízo acontece durante o aleitamento materno ${ }^{(12)}$

Sabemos que a prática do aleitamento materno exclusivo é recomendada por um período de seis meses e sob livre demanda. Após este período, a criança deve receber alimentos que complementem a sua nutrição até os dois anos, desde que seja uma vontade da criança e da mãe. Os benefícios do aleitamento materno, assim, podem ser constatados tanto no processo de crescimento e desenvolvimento de lactentes, como para a criança, a mãe, a família, a sociedade e o Estado. Para isso, é necessário que o aleitamento se inicie o mais precocemente possível, e o bebê seja colocado para mamar na sala de parto, na primeira meia hora após o parto, segundo recomendações do $\mathrm{MS}^{(2)}$.

Os resultados desta pesquisa apontam que $76 \%$ (38) dos bebês não haviam sido colocados ao seio na sala de parto, circunstância que pode contribuir para o estabelecimento do desmame precoce. Evidências científicas comprovam que a separação precoce de mães e bebês, logo após o nascimento, leva ao insucesso do aleitamento materno ${ }^{(13)}$.

Muito embora 74\% (37) das puérperas tenham referido um contato pele a pele logo após o parto, o que pode ser benéfico para ambos pois favorece a formação do vínculo afetivo mãe-filho, esse tipo de contato fica prejudicado nos partos cesáreos, quando mãe e bebê têm este momento prejudicado devido a uma série de procedimentos que precisam ser realizados $^{(11)}$.

Entre as puérperas entrevistadas, a taxa de cesariana foi de $26 \%$ (13), sendo que o Programa do MS considera, como ideal, uma taxa em torno de 15 a $20 \%$ para o total da população assistida. Aqui, é preciso considerar o grau de complexidade da assistência oferecida pela instituição em questão, que vem a ser uma referência para a gravidez de alto risco $^{(14)}$

Vários grupos de discussão temática foram formados voluntariamente com as puérperas entrevistadas e com as que se interessaram em participar. O objetivo do grupo era de informar, tirar dúvidas e ouvir as puérperas em relação à amamentação. Apesar de $80 \%$ (40) das puérperas negarem dúvidas sobre o tema durante as entrevistas, quando iniciamos o grupo e construímos o que deveria ser discutido, várias dúvidas surgiram. As mais freqüentes foram quais deveriam ser os cuidados com as mamas se houvesse ingurgitamento mamário; se elas deveriam dar mamadeira ao bebê se o leite estivesse fraco; até quantos meses era realmente importante amamentar e se o bebê deveria ser acordado para ser amamentado, entre outras. Estudos apontam que quando as mães recebem informações sobre o aleitamento materno, principalmente quando há uma participação ativa dos sujeitos, a autoconfiança, no período puerperal, fortalece a decisão da nutriz de iniciar e permanecer amamentando. As informações dão a ela segurança para cuidar do bebê e de si mesma ${ }^{(13,15)}$.

\section{CONCLUSÕES}

Ao observarmos, na prática, a importância da atenção que devemos dar ao aleitamento materno em todo ciclo gravídico-puerperal, e as possíveis consequências para a mulher e o recém-nascido, pudemos constatar que, apesar de muitos passos já terem sido dados, em direção à promoção, incentivo e apoio ao aleitamento materno em todo país, ainda existem lacunas nesta assistência que precisam ser 
avaliadas e preenchidas pelos profissionais.

Sem qualquer sombra de dúvidas, os profissionais de saúde que mantêm contato com gestantes e puérperas precisam estar atentos às oportunidades que surgem. Uma delas é que podemos exercer o papel de agentes multiplicadores de informação e apoiar, de forma concreta, a prática do aleitamento materno. Mesmo quando esta mulher, consciente e informada, opta por não amamentar, devemos procurar compreender, respeitar e apoiar sua decisão.

Várias considerações foram construídas em relação à visão que as puérperas apresentam quanto à assistência na prática da amamentação. As que receberam orientação explicitaram que se sentiam seguras para amamentar, demonstrando autoconfiança, conhecimento em relação aos benefícios para o binômio mãe-filho e mostrando uma postura de firmeza em relação à decisão de permanecer amamentando. Além de perceberem a atenção que o profissional Ihes dispensou, elas também fortaleceram o senso de valorização própria.

Já as puérperas que não foram orientadas perceberam claramente a diferença que a informação estava fazendo naquele momento. Elas não foram assistidas e identificaram o descompromisso e o desinteresse por parte de alguns profissionais. Demonstraram ainda insegurança e falta de confiança na sua própria capacidade para amamentar, dúvidas quanto ao valor nutritivo do seu leite e desconhecimento da importância de estar aleitando seu bebê.

Este estudo constatou que iniciativas, programas, pesquisas e normas vêm sendo criadas em prol da amamentação, nas últimas décadas, mas ainda é necessário um investimento continuado e o envolvimento de profissionais. Estes últimos devem ser capacitados e interessados em praticar a teoria, levando o conhecimento para o seu dia-a-dia, comprometendo-se consigo mesmo e com o outro. Os enfermeiros e demais integrantes das equipes de saúde devem assistir a mulher no seu ciclo gravídicopuerperal e em toda sua integralidade, independente de um sistema que, muitas vezes, atrofia, limita e engessa. Só assim, as mudanças vão ocorrer.

\section{REFERÊNCI AS}

1. Ministério da Saúde. Manual de Capacitação de Equipes de Unidades Básicas de Saúde na Iniciativa Unidade Básica Amiga da Amamentação - IUBAAM [CD-ROM] Brasília: Ministério da Saúde; 2003.

2. Ministério da Saúde; Secretaria de Políticas de Saúde. Área técnica de saúde da mulher. Parto, aborto e puerpério: Assistência humanizada à mulher. Brasília (Brasil): Ministério da Saúde; 2001.

3. Mascarenhas MLW, Albernaz EP, Silva MB, Silveira RB. Prevalência de aleitamento materno exclusivo nos 3 primeiros meses de vida e seus determinantes no Sul do Brasil. J. Pediatr. (Rio J.) [Internet]. 2006 [cited 2009 set 209]; 82(4):289-94. Available from: http: //www. scielo.br/pdf/jped/v82n4/v82n4a11.pdf.

4. Silva MBC, Moura MEB, Silva AO. Desmame precoce: representações sociais de mães. Rev. Eletr. Enf. [Internet]. 2007 [cited 2009 set 29]; 9(1): 31-50. Available

from:

http://www.fen.ufg. br/revista/v9/n1/pdf/v9n1a03.pdf.

5. Araújo MFM, Otto AFN, Schmitz BAS. Primeira Avaliação do cumprimento dos "Dez Passos para o Sucesso do Aleitamento Materno" nos Hospitais Amigos da Criança do Brasil. Rev. Bras. Saude Mater. Infant. [Internet]. 2003 [cited 2009 set 29];3(4):411-9. Available from: http: // www.scielo.br/pdf/rbsmi/v3n4/18886.pdf.

6. Souza LMBM. Promoção, proteção e apoio: Apoio? Representações sociais em aleitamento materno. Rio de Janeiro: Papel Virtual Editora; 2004.

7. Polit DF, Hungler BP. Fundamentos de pesquisa em enfermagem. 3rd ed. Porto Alegre: Artes Médicas; 1995.

8. Javorski M, Caetano LC, Vasconcelos MGL, Leite AM, Socchi CGS. As representações sociais do aleitamento materno para mães de prematuros em unidade de cuidado canguru. Rev Latino-am Enfermagem [Internet]. 2004 [cited 2009 set 29]; 12(6):890-8. Available from: http: //www.scielo. br/pdf/rlae/v12n6/v12n6a07.pdf.

9. Percegoni N, Araújo RMA, Silva MMS. Conhecimento sobre aleitamento materno de puérperas atendidas em dois hospitais de Viçosa, Minas Gerais. Rev. Nutr. [Internet]. 2002 [cited 2009 set 29];15(1):29-35. Available from: http://www.scielo.br/pdf/rn/v15n1/a04v15n1.pdf.

10. König $A B$, Fonseca $A D$, Gomes VOG. Representações sociais de adolescentes primíparas sobre "ser mãe". Rev. Eletr. Enfer. [Internet]. 2008; [cited 2009 set 29]; 10(2):405-13. Available from: http://www.fen.ufg.br/revista/v10/n2/v10n2a12.htm 11. Narchi NZ, Fernandes RAQ, Gomes MMF, Queiroz $M L$, Higasa DN. Análise da efetividade de um programa de incentivo ao aleitamento materno exclusivo em comunidade carente de São Paulo. Rev. Bras. Saude Mater. Infant. [Internet]. 2005 [cited 2009 set 29];5(1):87-92. Available from: http://www.scielo.br/pdf/rbsmi/v5n1/a11v05n1.pdf. 12. Melo AMCA, Cabral PC, Albino E, Moura LMD, Menezes AEB, Wanderley LG. Conhecimentos e atitudes sobre aleitamento materno em primíparas da cidade do Recife, Pernambuco. Rev. Bras. Saude Mater. Infant. [Internet]. 2002 [cited 2009 set 29]; 2(2):137-42. Available from: http://www.scielo.br/pdf/rbsmi/v2n2/17111.pdf.

13. Organização Mundial de Saúde. Evidências científicas dos dez passos para o sucesso do aleitamento materno. Brasília (Brasil); Ministério da saúde; 2001.

14. Ministério da Saúde. Secretaria de Políticas de 
Saúde. Área técnica de saúde da mulher. Parto, aborto e puerpério: Assistência humanizada à mulher. Brasília, DF; 2001.

15. Silva SC, Silva LR, Mathias LFB. O tempo médio entre o nascimento e a primeira mamada: o ideal e o real. Rev. Eletr. Enf. [Internet]. 2008; [cited 2008 fev 04]; 10(3):654-61. Available from: http://www. fen.ufg. br/revista/v10/n3/v10n3a11.htm

Artigo recebido em 14.08.08.

Aprovado para publicação em 28.05.09.

Artigo publicado em 30.09.09. 